\title{
Distribution of DDT in a Typical DDT Waste Contaminated Site
}

\author{
Wenbin Liu · Changliang Li $\cdot$ Minghui Zheng · \\ Li Wang · Sumei Li $\cdot$ Te Ba $\cdot$ Guijin Su • \\ Lirong Gao $\cdot$ Lifei Zhang
}

Received: 12 July 2007/Accepted: 11 January 2008/Published online: 22 February 2008

(C) Springer Science+Business Media, LLC 2008

\begin{abstract}
Serious pollution was found in the soil under a historically DDT workshop and the highest level of $\sum$ DDT was $2682.86 \mathrm{mg} / \mathrm{kg}$. The vertical distribution of DDT shows that the levels of DDT decreased significantly with increase of depth, which mainly because the infiltration of rainwater was inhibited by the cement or brick surface. The DDT polluted soil area was $6,814 \mathrm{~m}^{2}$ and the polluted soil volume $4,398 \mathrm{~m}^{3}$ above $10 \mathrm{mg} / \mathrm{kg}$. The ratio of (DDE + DDD) to DDT showed that part of the $p, p^{\prime}$-DDT was degraded to DDD and DDE in the soil.
\end{abstract}

Keywords DDE $\cdot$ Waste $\cdot$ Infiltration $\cdot$ Degradation

DDT (1,1,1-trichloro-2,2-bis( $p$-chlorophenyl) ethane) has been widely used throughout the world to control arthropod disease-vectors and agricultural pests. Although DDT is banned in developed nations, it is still being used in developing nations due to its cost effectiveness and broadspectrum activity. DDE (1,1-dichloro-2,2-bis( $p$-chlorophenyl) ethylene) and DDD (1,1-dichloro-2,2-bis ( $p$-chlorophenyl) ethane) are the two major metabolites of DDT usually present together with the parent compound in DDT-contaminated soils (Megharaj et al. 2000). The US Environmental Protection Agency has categorized DDT

W. Liu $(\bowtie) \cdot$ C. Li $\cdot$ M. Zheng $\cdot$ S. Li · T. Ba $~$ G. Su •

L. Gao $\cdot$ L. Zhang

Research Center for Eco-Environmental Sciences, Chinese

Academy Sciences, Beijing 100085, China

e-mail: liuwb@rcees.ac.cn

C. Li $\cdot$ L. Wang $\cdot$ S. Li

Environmental Engineering Department, University of Science and Technology Beijing, Beijing 100083, China and its residues, DDE and DDD, as priority pollutants (Keith and Telliard 1979). China was a major producer and consumer of DDT in the last century resulting in high residual levels of DDT and its metabolites in various environmental media and ecological compartments (Tao et al. 2007). The total production of technical DDT was about 0.4 million tons, which accounted for $20 \%$ of total world production (Zhang et al. 2002; Yang et al. 2005). Although extensive application has been banned in agriculture since 1992 and production restricted, there remain extensive amounts of DDT waste and waste contaminated sites (WCS) that are still releasing DDT to the environment. Although the residue levels of DDT in the environment have considerably declined in the past 20 years, they are still detectable in various environmental matrices (Wu et al. 1999; Li et al. 2001).

This study examines a major Chinese DDT plant (ZHD pesticide plant) of China. The plant was built in 1968 and produced DDT until the Chinese government restricted DDT production in 1983. Annual output was about 1,500 tons with the highest output of 2,500 tons in 1982. Although the DDT production facility has been removed in the past, the soil under workshop has not been disposed of and may contain high levels of DDT. Thus, a series of samples from the waste workshop and nearby soil were collected to investigate the residue and transformation of DDT.

\section{Materials and Methods}

The soil samples were collected in November 2006. Figure 1 presents all the sample sites.

Panes A and B are the historical DDT production workshop and packing workshop, respectively. Sample site 1 is near the center of the WCS. On the basis of the 


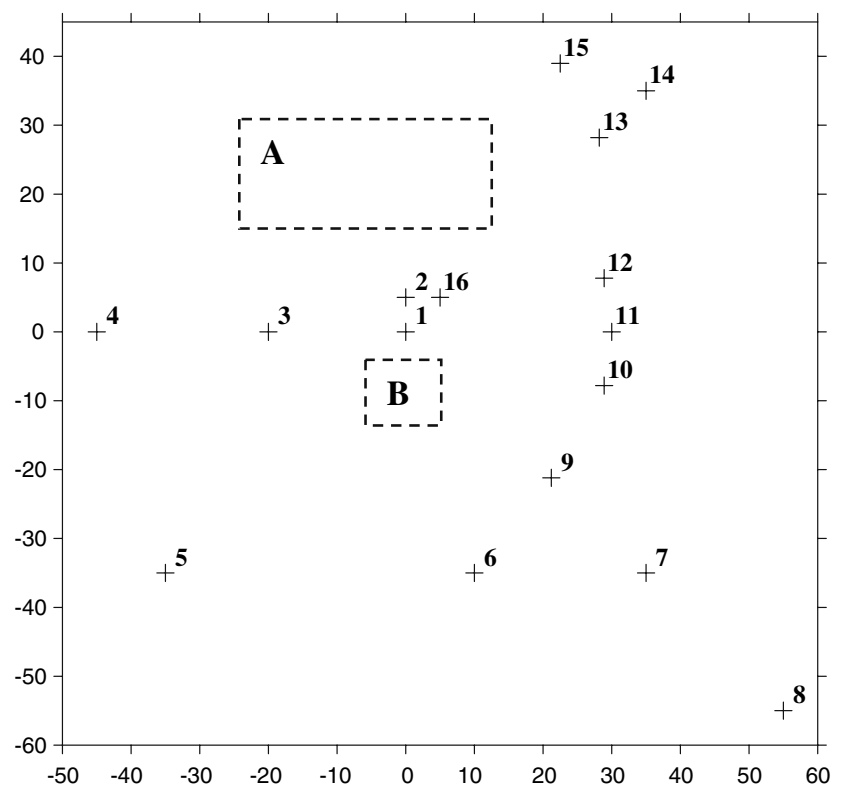

Fig. 1 The distribution of sample sites in the WCS

situation of the workshop and wind direction, 40 samples from 16 sample sites collected using the soil sample collector (Eijkekamp, Netherlands). In each sample site, the surface sample $(0-20 \mathrm{~cm})$ was collected after removing the surface weed and brick etc. In addition, soil core samples from 20 to $150 \mathrm{~cm}$ depth were collected at some sites in order to investigate the vertical distribution and transformation of DDT. These samples included 20-40, 40-60, $60-80,80-100 \mathrm{~cm}$ depths at sites 3 and $15,20-40,40-60$, $60-80,80-100,100-120$, and $120-150 \mathrm{~cm}$ depths at sites 1 and 2; and 20-40 cm depths at sites 4, 13, and 14 .

The DDT analytical procedure was a modification of the standard of China "Soil quality-Determination of BHC and DDT-Gas chromatography (GB/T 14550-93)" method. Approximately $10 \mathrm{~g}$ of soil was mixed with $5 \mathrm{~g} \mathrm{Na}_{2} \mathrm{SO}_{4}$ prior to the addition of $50 \mathrm{~mL}$ of hexane/acetone $(1: 1 \mathrm{v} / \mathrm{v})$. The mixture was allowed to stand overnight (about $12 \mathrm{~h}$ ) and extracted for $4 \mathrm{~h}$ using Soxhlet Extraction. The solution was washed with $100 \mathrm{~mL} \mathrm{Na} \mathrm{SO}_{4}$ solution and purified with $5 \mathrm{~mL} \mathrm{H}_{2} \mathrm{SO}_{4}$. Then the solution was concentrated and analyzed with an Agilent 6890A Gas Chromatograph equipped with a ${ }^{63} \mathrm{Ni}$ Electron Capture Detector (GC/ECD) and a HP-5 fused silica capillary column. The oven temperature was elevated from 60 to $235^{\circ} \mathrm{C}$ at a rate of $25^{\circ} \mathrm{C} / \mathrm{min}$ and held for $2 \mathrm{~min}$ at $235^{\circ} \mathrm{C}$, and programmed to $250^{\circ} \mathrm{C}$ at $2^{\circ} \mathrm{C} / \mathrm{min}$ and held for $5 \mathrm{~min}$ at $250^{\circ} \mathrm{C}$, and then increased to $280^{\circ} \mathrm{C}$ at $10^{\circ} \mathrm{C} / \mathrm{min}$ and held for $5 \mathrm{~min}$ at $280^{\circ} \mathrm{C}$.

\section{Results and Discussion}

Table 1 presents the DDT levels in the surface soil samples.
Table 1 DDT levels in the surface soil samples $(\mathrm{mg} / \mathrm{kg})$

\begin{tabular}{lccccc}
\hline Site & $p, p^{\prime}$-DDE & $p, p^{\prime}$-DDD & $o, p^{\prime}$-DDT & $p, p^{\prime}$-DDT & $\sum$ DDT \\
\hline 1 & 390.2 & 191.5 & 596.7 & 1504.5 & 2682.9 \\
2 & 4.11 & 8.70 & 11.5 & 25.5 & 49.8 \\
3 & 26.0 & 87.7 & 146.1 & 380.0 & 639.8 \\
4 & 1.74 & 0.14 & 1.72 & 3.06 & 6.66 \\
5 & 3.06 & 0.14 & 2.76 & 3.22 & 9.18 \\
6 & 1.71 & 0.40 & 3.18 & 8.95 & 14.2 \\
7 & 2.87 & 0.47 & 3.48 & 8.05 & 14.9 \\
8 & 7.25 & 0.78 & 8.20 & 27.7 & 43.9 \\
9 & 29.1 & 6.35 & 8.26 & 20.4 & 64.1 \\
10 & 27.5 & 30.6 & 58.4 & 135.9 & 252.5 \\
11 & 19.7 & 18.7 & 21.4 & 47.8 & 107.4 \\
12 & 3.72 & 4.79 & 3.98 & 14.3 & 26.8 \\
13 & 0.71 & 0.09 & 1.17 & 2.29 & 4.26 \\
14 & 0.06 & 0.02 & 0.11 & 0.44 & 0.63 \\
15 & 26.3 & 22.0 & 131.1 & 102.0 & 281.3 \\
16 & 229.0 & 99.2 & 169.8 & 525.3 & 1023.3 \\
\hline
\end{tabular}

For the surface soil samples, the level order of the four DDT isomers was $p, p^{\prime}$-DDT $>o, p^{\prime}$-DDT $>p, p^{\prime}$-DDE $>$ $p, p^{\prime}$-DDD. The range of $p, p^{\prime}$-DDT was between 0.44 and $1504.5 \mathrm{mg} / \mathrm{kg}$, while the $o, p^{\prime}$-DDT was between 0.11 and $596.7 \mathrm{mg} / \mathrm{kg}, p, p^{\prime}$-DDE between 0.06 and $390.2 \mathrm{mg} / \mathrm{kg}$ and $p, p^{\prime}$-DDD between 0.02 and $191.5 \mathrm{mg} / \mathrm{kg}$, respectively. Total DDT (sum of four DDT isomers) was between 0.62 and $2682.9 \mathrm{mg} / \mathrm{kg}$. The isoline map of DDT contamination in the surface soil, protracted using Kriging interpolation, is shown in Fig. 2.

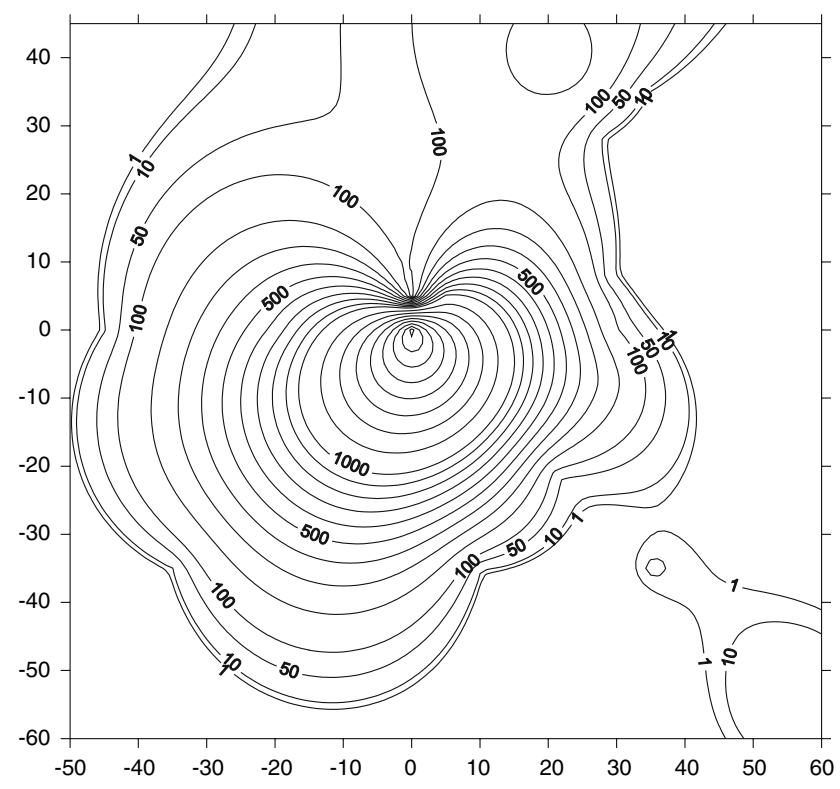

Fig. 2 Isoline map of DDT in the surface soil samples 
Figure 2 shows the polluted zone to be much like a circle with serious pollution in the center of the site and lesser levels in the margins. The highest level of contamination $\left(\sum D D T\right)$ was $2682.9 \mathrm{mg} / \mathrm{kg}$ at site 1 , in the center of the WCS. Among the samples, $\sum D D T$ was above $500 \mathrm{mg} / \mathrm{kg}$ at 3 sites, above $50 \mathrm{mg} / \mathrm{kg}$ at 4 sites, above $10 \mathrm{mg} / \mathrm{kg}$ at 5 sites, and below $10 \mathrm{mg} / \mathrm{kg}$ at 4 sites. Surface areas for the respective polluted surface soils are presented in Table 2.

Nearly all of the workshop surface and nearby soils were covered by brick or cement due to the needs of the DDT production. This was also helpful to prevent infiltration of rainwater and transmission of DDT to the deep soil. The DDT levels decreased with depth increased. The vertical distribution of DDT at sites 1,2, 3, and 15 are presented in Fig. 3.

Figure 3 shows that DDT levels decreased in the central area of the WCS from $2682.86 \mathrm{mg} / \mathrm{kg}$ at the surface to $3.44 \mathrm{mg} / \mathrm{kg}$ at $1.5 \mathrm{~m}$ depth. DDT levels at all sites were near or lower than $10 \mathrm{mg} / \mathrm{kg}$ by $1.2 \mathrm{~m}$ depth. Basically, the levels of DDT decreased significantly with depth increased, which mainly due to the infiltration of rainwater was inhibited by the cement or brick surface of the WCS.

Because of the isotropy of the DDT transmission in the soil, the DDT distribution could be simulated with a cone model. For same depth soils, DDT levels in the center are highest and those near the margin are lower, while for one site DDT levels decreased with the depth of soil. In this study, $10 \mathrm{mg} / \mathrm{kg}$ was selected as the suggested DDT criteria. Thus, the DDT polluted area was estimated at $6,814 \mathrm{~m}^{2}$ and the polluted soil was estimated $4,398 \mathrm{~m}^{3}$ or 6,597 tons, given the soil density of 1.5 tons $/ \mathrm{m}^{3}$.

DDT can be biodegraded to DDE under aerobic conditions and to DDD under anaerobic conditions. Further, the relative concentration of the parent DDT compound and its metabolites, DDD and DDE, can also be used as an index for assessing possible pollution sources (Doong et al. 2002; Villa et al. 2006). DDT compositions in this study varied significantly. The percentage of $p, p^{\prime}$-DDT in the surface soil samples ranged from $31.8 \%$ to $69.8 \%$ with a mean $51.4 \%$, while the percentage of $p, p^{\prime}$-DDT in the depth soil samples ranged from $18.6 \%$ to $82.9 \%$ with a mean $55.4 \%$. The ratio of (DDE + DDD) to DDT is greater than 0.5 and can be thought to be subjected to a long-term weathering. Here the mean ratio of (DDE + DDD) to DDT in the samples was 0.61 , which suggests that the degradation occurred significantly after the official ban of DDT in 1983. In China, commercial DDT was composed of $75 \% p, p^{\prime}-$

Table 2 The areas of the polluted surface soil of the WCS

\begin{tabular}{llllll}
\hline Levels of DDT $(\mathrm{mg} / \mathrm{kg})$ & $>0$ & $>1$ & $>10$ & $>100$ & $>1000$ \\
\hline Areas $\left(\mathrm{m}^{2}\right)$ & 7369 & 7305 & 6814 & 4453 & 641 \\
\hline
\end{tabular}

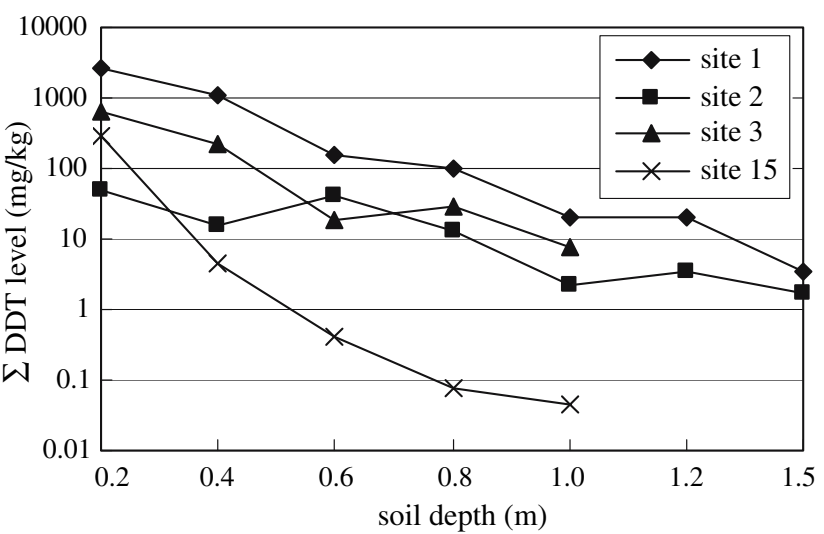

Fig. 3 The vertical distribution of DDT in the WCS

DDT, $15 \% o, p^{\prime}$-DDT, $5 \% p, p^{\prime}$-DDE, $0.5 \% p, p^{\prime}$-DDD and about $4.5 \%$ other impurities. The percentage of DDE in the samples ranged from $2.6 \%$ to $55.8 \%$ with a mean $14.8 \%$, while DDD ranged from $1.5 \%$ to $25 \%$ with a mean $8.3 \%$. The percentage of DDE and DDD increased significantly than those in the commercial DDT, which means that part of the $p, p^{\prime}$-DDT was degraded to DDD and DDE in the contaminated sites.

Acknowledgments This study is supported by Chinese Academy of Sciences (Grant No.KZCX2-YW-420) and National Natural Science Foundation of China (Grant No. 20621703).

\section{References}

Doong R, Sun Y, Liao P, Peng C, Wu S (2002) Distribution and fate of organochlorine pesticide residues in sediments from the selected rivers in Taiwan. Chemosphere 48:237-246

Keith LH, Telliard WA (1979) ES\&T Special Report: priority pollutants: I-a perspective view. Environ Sci Technol 13:416-423

Li Y, Cai D, Shan Z, Zhu Z (2001) Gridded usage inventories of technical hexachlorocyclohexane and lindane for China with 1/ $6^{\circ}$ latitude by $1 / 4^{\circ}$ longitude resolution. Arch Environ Contam Toxicol 41:261-266

Megharaj M, Kantachote D, Singleton I, Naidu R (2000) Effects of long-term contamination of DDT on soil microflora with special reference to soil algae and algal transformation of DDT. Environ Pollut 109:35-42

Tao S, Li B, He X, Liu W, Shi Z (2007) Spatial and temporal variations and possible sources of dichlorodiphenyltrichloroethane (DDT) and its metabolites in rivers in Tianjin, China. Chemosphere 68:10-16

Villa R, Dores E, Carbo L, Cunha M (2006) Dissipation of DDT in a heavily contaminated soil in Mato Grosso, Brazil. Chemosphere 64:549-554

Wu Y, Zhang J, Zhou Q (1999) Persistent organochlorine residues in sediments from Chinese river/estuary systems. Environ Pollut 105:143-150

Yang R, Jiang G, Zhou Q, Yuan C, Shi J (2005) Occurrence and distribution of organochlorine pesticides (HCH and DDT) in sediments collected from East China Sea. Environ Int 31:799-804

Zhang G, Parker A, House A, Mai B, Li X, Kang Y, Wang Z (2002) Sedimentary records of DDT and HCH in the Pearl River delta, South China. Environ Sci Technol 36:3671-3677 